\title{
Boru profilli gemi jeneratör kaidelerinin titreşim açısından analitik ve sayısal analizi
}

\author{
Adil YÜCEL*, Alaeddin ARPACI, \\ Enes AKPOLAT, Merve EROL, Utkucan ÖZDEMIR \\ İstanbul Teknik Üniversitesi, Makina Fakültesi, Makina Mühendisliği Bölümü, Gümüşsuyu Kampüsü, \\ Istanbul.
}

Geliş Tarihi (Received Date): 25.09.2019

Kabul Tarihi (Accepted Date): 05.05.2020

$\ddot{\mathbf{O} z}$

Gemiler, çok büyük ve karmaşık yapılar olduklarından bünyelerinde titreşim kaynă̆ı sayılabilecek bir çok eleman bulundurmaktadırlar. Bu çalışmada, gemi üzerinde yerel titreşimlere neden olan gemi jeneratör setleri için titreşim sönümleyici görevi gören ve farklı açılarda tasarlanmış boru profillerden oluşan tabla tipi 11 farklı kaide tasarımı üzerinde durulmuştur. Bu yapılar hem analitik hem de sonlu eleman yöntemiyle incelenmiştir. Çalışma, genel olarak, gemi jeneratör seti ve kaidelerinin katı modelleme yazılımıyla üç boyutlu katı modellerinin oluşturulması ve sonlu eleman metodu ile modal ve toplam deformasyon analizlerine dayanmaktadır. Bu incelemeler sonucunda hangi tasarımın titreşim sönümleme açısından en iyi sonucu verdiği belirlenmiştir.

Anahtar kelimeler: Gemi titreşimleri, modal analiz, jeneratör kaideleri.

\section{Analytical and numerical vibration analyses of marine genset foundations with pipe profiles}

\begin{abstract}
Since ships are very large and complex structures, they contain many members acting as vibration sources one of which is a marine genset. In this study, 11 different table-type marine genset foundation designs which are constructed using pipe profiles with various angles and which are acting as vibration reducers, have been investigated. These
\end{abstract}

\footnotetext{
*Adil YÜCEL, adil.yucel@itu.edu.tr, http://orcid.org/0000-0003-2384-2473

Alaeddin ARPACI, arpacial@itu.edu.tr, http://orcid.org/0000-0002-4085-1868

Enes AKPOLAT, aakpolatenes@gmail.com, http://orcid.org/0000-0003-2981-7017

Merve EROL, erolmerve94@gmail.com, http://orcid.org/0000-0002-4285-9302

Utkucan ÖZDEMIR, ozdemirutkucan@gmail.com, http://orcid.org/0000-0002-5787-0512
} 
structures have been analyzed using both analytical and finite element methods. The study is generally based on solid modelling, modal and total deformation analyses of genset foundations using finite element method. As a result of these analyses, the design of the genset foundation which is acting as vibration reducer optimally, has been determined.

Keywords: Ship vibrations, modal Analysis, genset foundations.

\section{Giriş}

Günümüzdeki gemiler, içerisinde birçok mekanik ve elektronik ekipman bulunduran kompleks yapılardır. Teknolojinin gelişmesiyle yapılan çalışmalar artmış, bu çalışmalar gemi sektöründe de etkilerini göstermiştir. Deniz taşımacılığına günden güne artan talep, gemi inşaatı ve gemi makinaları sektörünü pozitif yönde ivmelenen bir rekabet alanı haline getirmiştir. Bu talebin karşılanması için yapılan yeni tasarımlarda gemiler giderek hızlandırılmakta, hafifletilmekte ve boyutları büyütülmektedir. Bu tasarımların gemide emniyet ve konfor kriterlerinin gözetilerek oluşturulmasında, titreşim ve akustik analizler büyük önem arz etmektedir. Gemilerde titreşimin iç ve diş kaynaklar olmak üzere iki temel unsuru vardır. Ana makina, jeneratörler, pervane şaftı vb. gibi unsurlar iç kaynaklara örnek olarak verilebilirken dalga, rüzgâr, akıntı veya gemideki dengesiz yükleme durumları dış kaynaklara örnek verilebilir. İstenmeyen bu titreşimler, gemilerde büyük hasarlara neden olabilmektedir. Yolcu ve personelin seyahat kalitesi ve güvenliği ile çalışan ekipmanların performansı, oluşan titreşimlerden oldukça etkilenmektedir. Ağır yıkıcı sonuçlara dahi sebep olabilen titreşim problemi, gemide tasarım aşamasında öncelik verilmesi gereken konulardan biridir [1]. Bir geminin tasarımından imalatına kadar geçen süre boyunca, titreşim problemini önlemek adına alınabilecek çeşitli önlemler bulunmaktadır. Bu çalışmada, yerel titreşim kaynaklarının en önemlilerinden biri olan gemi jeneratörlerinin titreşim sönümleyici görevi gören özel tasarım kaideleri üzerinde duracağız. Çalışmanın sonucunda, konstrüktif parametreleri değiştirilerek yapılan analizlerin değerlendirilmesiyle en iyi sönümlemeyi hangi tasarımın yaptığ konusunda bir fikir sahibi olunacaktır. Bir gemi jeneratör setinden kaynaklanan titreşim sorunu, üreticilerin büyük bir problem olarak gördükleri ve gelişen teknoloji ile sürekli yeni çözümler geliştirmeye uğraştıkları bir husus olmuştur [2]. Yapılan incelemelerde jeneratör setinin içindeki motorun en büyük titreşim kaynağı olduğu saptandığından, literatürde genel olarak jeneratörün dinamiği ve titreşim için çözüm önerilerine yoğunlaşılmıştır.

V. S. Chavan, R. Askhedkar ve S. B. Sanap yaptıkları çalışmada motor titreşimlerinin üreticiler açısından önemli bir sorun olduğunu belirtmiş ve gaz basıncı ile dengesizlik kuvvetlerinden doğan motor tahrik kuvvetlerinin bu titreşimlerin kaynağı olduğunu saptamışlardır. Bu sorunun etkilerini azaltmak için titreşim takozları kullanmışlardır. Titreşim takozları titreşimi sönümlemek ve hasara neden olan kuvvetleri azaltmak için kullanılan elemanlardır. Bu takozlar kütle-yay-damper olarak modellenmiş bir sistemden meydana gelmiş olup motor ve ana şasi titreşimlerini azaltan titreşim takozları üzerine monte edilmiştir. Tek bir titreşim takozu, model için ve motor yapısının bir parçası olan üst plaka ve ana şasiye bağlı alt plakanın frekans cevabı için analiz edilmiştir [3]. H. Fucai, Y. Jianguo ve Z. Qingming'e göre gemideki gürültü oranının azaltılması, geminin ana titreşim kaynağının izolasyonunda daha esnek kurulumlar kullanılmasına bağlıdır. Tek katmanlı titreşim yalıtım sistemi gibi esneklik koşulunda kurulan donanımlara sahip ana titreşim kaynağında, titreşim azaltma seviyesinin yaklaşık 20-25 dB olduğu 
belirtilmiştir. Ancak bu makaledeki temel tartışma konusu, iki katmanlı titreşim yalıtımının ve transfer fonksiyonu eğrilerinin dinamik karakteristiklerinin farklı kütle ve rijitlik oranı altında elde edilmesidir. İki katmanlı titreşim izolasyonu için, rijitlik oranının arttığı ya da kütle oranının azaldığı ihtimalinde titreşim enerjisi aktarımının azalmasının ve izolasyon etkisinin geliştirilmesinin birçok yararı olduğu gösterilmektedir. Ayrıca tek katmanlı titreşim yalıtımına göre iki katmanlı titreşim yalıtımının daha çok yararı olduğu gerçek testlerle onaylanmıştır [4]. Başka bir çalışmada ise, titreşimli yüklere bağlı zeminlerin tepkisini belirleyen analiz yöntemleri tartışılmaktadır. Bir makina zemini tasarımı genellikle temel zeminin bir ya da iki serbestlik dereceli yay-kütle-damper modeli olarak idealleştirilmesiyle yapılmaktadır. Çoğu makina zemin tasarımları, yüzey dayanağı ve zemin yayı olarak işlem görmüş ve sönümleme değerleri elastik yarım uzay örnekseli kullanılarak belirlenmiştir. Ayrıca gözlenen makina zemini tepkileri ve önceden tahmin edilen kısa bir tartışma da sunulmaktadır [5]. Gerb Mühendisliğin yaptığ1 araştırmalara göre; büyük gaz ve dizel motorlar birçok amaç için kullanılmaktadır. Bu motorlar için kurulan zeminler etkili ve ekonomik olmak zorundadır. Bu ekipmanın elastik mesneti bu gereksinimleri karşılar. İşlem boyunca motor tarafindan üretilen salınımlı kuvvet ve momentler içten dengelenmiştir. Geriye kalan kuvvet ve momentler ise zemine aktarılmaktadır. Normalde motor ve jeneratör ortak bir rijit zemin üzerinde sıralanmıştır. Küçük ekipmanlar olduğu takdirde bu genellikle çelik bir çerçeve olacaktır. Daha büyük jeneratörler genellikle dinamik ve statik kuvvetlerin alt zemin ya da alt yap1 içine yöneltilerek uygun gelen bir kütleyle motorun dinamik kuvvetlerinin dengesinin sağlandığı beton bir zemine sahiptirler. Ancak çok büyük bir beton zemin bile dinamik kuvvetlerin alt zemin içine ve dolayısıyla yapıya ve çevresine aktarılmasını önleyemez. $\mathrm{Bu}$ durum titreşim problemi yaratabilir. Yerleştirme problemleri pahalı bir kazıklı temel (zemin) ile çözülebilirken rahatsız edici dinamik kuvvetlerin aktarımı sıradan zemin yöntemleriyle nadiren sınırlandırılır. Zeminde yapılacak sonradan bir değişiklik pahalıdır ve her durumda bu çok büyük bir çalışma gerektirir. Ayrıca uzun bir süre için jeneratörün faaliyetini durdurması demektir [6]. G. E. Clunis ve S. J. Bradley yaptıkları çalışmada 60 $\mathrm{kW}$ 'lık dizel bir jeneratör için gürültü ve titreşim izolasyon sisteminin geliştirilmesi konusunda mühendislik tasarım işleminin bir taslağını sunmaktadır. $\mathrm{Bu}$ taslak, keşfedilmiş ve iskontolu olan konsept dizaynlarla ilgili bir tartışmadan, sonlu elemanlar ile değerlendirmeden geçip, bütün akışkan ve diğer esnek bağlantıların dizaynı, akustik mahfaza dizaynı ve yapıyı da kapsayan gemi güvertesi ara yüzleri için gereksinimlerle ilgili son tasarım detaylarıyla hazırlanmıştır. $\mathrm{Bu}$ araştırmada kullanılan gemilerin öncelikli rolü su altı gürültü araştırma ve ölçümleridir, bu yüzden gemideki makinalar için de düşük su altı gürültü seviyesi gereklidir. Öncelikli olarak yardımcı makina olarak adlandırılan dizel jeneratör hususunda çalışma yapılma ihtiyacı duyulmuş ve bu konuda jeneratör için çift dayanak sistemi kullanılması planlanmıştır. Buna ek olarak akustik mahfaza sistemi de kurulmuştur, yani jeneratörün çevresi akustik yalıtımla kapatılmıştır. Çift dayanak sisteminde yayların da kullanıldığı belirtilmiştir [7]. D. You, L. Sun, S. Ai ve Y. Liu çalışmalarında bir geminin motor-dayanak sisteminin titreşim karakteristiklerini belirlemek için modal analiz yapılmış ve bu analiz sonucu doğal frekanslar ve motor-dayanak sisteminin başlıca modları elde edilmiştir. Bu noktada dayanağın dinamik rijitliği daha ayrıntılı bir şekilde tartışılmıştır ve mühendislik alanında süper pozisyon prensibiyle dinamik yer değiştirme kalibre edilmiştir. Yapılan hesaplamalarda dayanağın rijitliğinin ortaya çıkardığı gereksinimler gösterilmiş ve buna göre dizayn aşamasına gidilmiştir [8]. M. Daifuku, T. Nishizu, A. Takezawa, M. Kitamura, H. Terashita ve Y. Ohtsuki tarafından yapılan başka bir çalışmada ise makina dairesinde bulunan jeneratörün altına takviye yöntemi ile titreşimin optimizasyonu planlanmıştır. Bu titreşim karakteristiğini artırmak için topoloji optimizasyonu en uygun 
metot olarak seçilmiştir. Bunun nedeni topoloji optimizasyonunun hemen her zemine rahatlıkla uygulanabilmesi olmuştur. Öncelikle titreşim yapan eleman sonlu elemanlar yöntemi ile modellenmiştir. Bu analizlerden çıkan sonuçlara göre dinamik karakteristik araştırılmış, daha sonra yük dağılımına göre titreşimi azaltacak bir eleman tasarımına gidilmiştir. Bu tasarımda boyuna ve enine yapı elemanları güçlendirici ve titreşim azaltıcı şekilde optimize edilmeye çalışılmıştır. Daha önceden boyutları belirlenmiş bu yapı elemanları farklı şekillerde ve boyutlarda analiz edilmiştir. Sonrasında çalışma optimizasyon kısmı için gerekli metodların ve algoritmaların geliştirilmesi ile devam etmiştir. Sonuç olarak uygun frekansta çalışacak, yeterli dayanıma sahip ve en önemlisi titreşim azaltan bir tasarım geliştirmişlerdir [9]. S. P. Mogal, R. K. Behera ve S. Y. Pawar, bir jeneratörün titreşim önleyici desteklerle (kauçuk, poliüretan köpük, yün-keçeden yapılan) çalışmasıyla ortaya çıkan yakın alan gürültü seviyelerinin değerlendirilmesi ve kontrolü üzerinde deneysel olarak çalışmışlardır [10]. S. R. Bognatz, deneysel modal analiz (EMA) ve operasyonel modal analiz (OMA) yöntemlerinin sağladığı önemli kazançlar sayesinde dönen makina titreşim problemlerini detaylı şekilde incelemeyi amaçlamıştır [11]. S. Sadok, çalışmasında, dönen makinaları ve viskoz elastik amortisörleri taşıyan yapının dinamik karakterlerini tartışmıştır [12]. K. Listewnik ise jeneratör titreşimlerinin gemi, titreşim kayıtları, su altı gürültüsü ve gemi hareketleri üzerindeki etkilerini göstermiştir [13]. S. H. Gawande ve diğerleri, dört zamanlı çok silindirli dizel motor kaplin jeneratör sisteminin serbest ve zorlanmış titreşimlerini analiz etmiştir. Çalışmada, sistemdeki burulma titreşiminin doğal frekanslarını bulmak için değiştirilmiş Holzer yöntemini kullanmayı tercih etmişlerdir [14]. G. P. Anton ve diğerleri, sonlu elemanlar modelini kullanarak NVH test ve hesaplama korelasyonunu incelemişlerdir. İnceleme için geliştirilmiş bir FE modeli kullanılarak arayüz noktalarındaki titreşim seviyesinin (düşük ve orta frekans aralığı) mutlak değerlerini elde etmişlerdir [15]. A. Livshits ise çalışmasında, türbinli jeneratörler için farklı türdeki kaideleri ve bu kaidelerin dinamik yükler altındaki davranışlarını araştırmıştır [16]. S. Adhikari, bir termik santral için bir turbo jeneratör kaidesi tasarımı üzerinde çalışmış ve bu çalışması ile uluslararası standartları göz önünde bulundurarak turbo jeneratör kaideleri tasarımındaki büyük önem arz eden parçaları ön plana çıkarmıştır [17]. K. Murali ve diğerleri, doğal frekanslar ve zorlanmış frekans cevaplarının farklı sınır şartlarında yapının güvenliğini sorunlu hale getirmesi üzerine bir çalışma ortaya koymuşlardır [18]. D. C. Lee ve diğerleri ise teorik ve deneysel bir model olarak, bir konteyner gemisindeki elastik kaideye sahip bir dizel motorlu jeneratör seti üzerinde çalışarak, dinamik davranışı ve yapı kaynaklı gürültünün iletimi üzerinde detaylı bir çalışma gerçekleştirmişlerdir [19]. P. B. Aher ve S. K. Malave, sonlu elemanlar yöntemi ile dizel jeneratör setlerinin sayısal simülasyonunu gerçekleştirmişlerdir. Motor ve alternatör kaidelerinin analizi için gezen nokta analizi adı verilen bir frekans cevabı yöntemi kullanmışlardır. Bunun yanısıra çalışmada, kaidelerin yerel dinamik rijitliği üzerine çalışılmış ve ikaz kuvvetlerinin yapıya nasıl sirayet ettiği gözlemlenmiştir [20]. O. S. Adeoye ve diğerlerinin yaptığ 1 çalışmada, jeneratör setlerinde, izolasyon yoluyla titreşimi engelleme, sönümleme yoluyla ise de titreşim enerjisini sistemden çekme üzerine çalışmalar irdelenmiştir. Genelde çalışma içerisinde elastomerik izolasyonlar, yay izolatörler ve ivmeölçerler üzerinde durulmuştur [21]. N. Dimbale ve diğerlerinin yaptığ 1 çalışmada ise SL90 tipi sıralı 6-silindirli jeneratörün birincil ve ikincil momentlerini elde etmek için kullanılan basitleştirilmiş bir dinamik titreşim analizi yaklaşımı üzerinde durulmuştur. Titreşimleri azaltmak için ele alınan jeneratör farklı silindir ve ateşleme konfigürasyonlarındaki dengesiz kuvvet ve momentler için yeniden analiz edilmiştir. Hatta bunun için özel bir C++ kodu yazılmıştır [22]. 


\section{Amaç ve kapsam}

$\mathrm{Bu}$ çalışmada, bir gemi jeneratörünün çalışma esnasında oluşturduğu titreşimlerin, jeneratörden gemi makina dairesine ve gemiye olan etkisinin azaltılması amacı ile bir kaide (foundation) tasarımı amaçlanmıştır. Gemi jeneratör seti ve alt kısmına yerleştirilecek kaideler teorik olarak modellenip sonlu eleman yöntemiyle sayısal olarak çözümlenmiştir. Sonuçların doğruluğu amacı ile gemi jeneratörleri ve kaideler bir gemi modeli üzerine yerleştirilmiş ve bu gemi modeli üzerinde analizleri yapılmıştır.

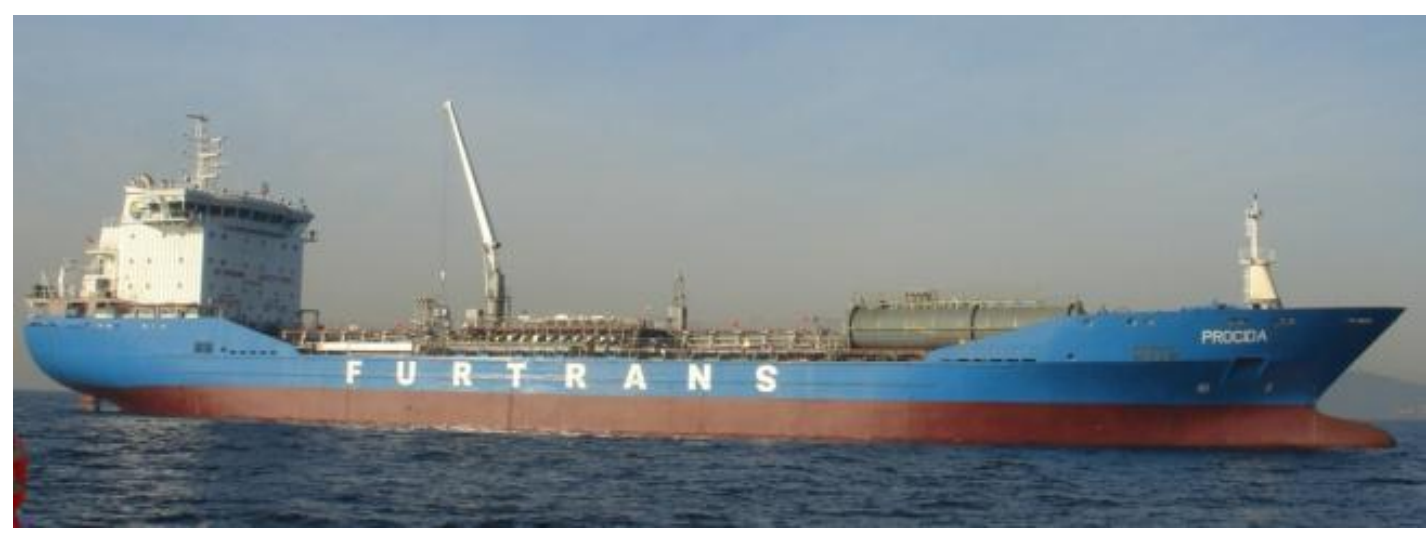

Şekil 1. Procida gemisi.

Çalışmada kullanılan ve üretim kodu CT75 olan bu gemi [23], çeşitli kimyasalları taşımak amacıyla tasarlanmış olan bir kimyasal tankerdir (Şekil 1). Gemiye yerleştirilmek üzere jeneratör seti olarak Wärtsilä marka jeneratör seti seçilmiş olup bu markanın "Wärtsilä 20" modeli tercih edilmiştir (Şekil 2).

Bu çalışmada, gemi jeneratörü ve gemi makina dairesi zemini arasında yer alan, çapı ve et kalınlığı sabit olan boru profillerin imal destek açıları değiştirilerek titreşim sönümleme ve mukavemet bakımından incelemesi yapılmıştır. Wärtsilä jeneratör setleri dünya çapında tanınan, bünyesinde jeneratör ve motoru birlikte olacak şekilde ortak bir taban üzerinde bulunduran makinalardır. Bu markaya ait tüm setler orta devirli makinalar olup, ağır yakıt tüketmektedirler.

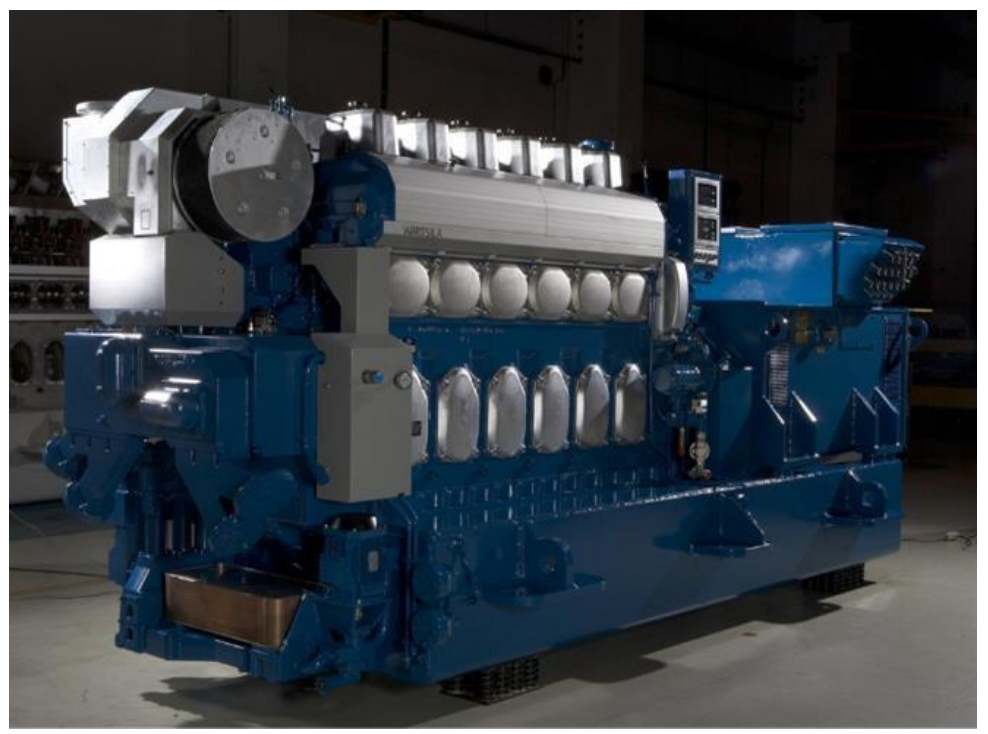

Şekil 2. Wartsila 20 jeneratör seti. 
Çalışmada kullanılan jeneratör setinin teknik özellikleri aşağıdaki Tablo 1'de belirtilmiştir.

Tablo 1. Wartsila 20 jeneratör seti teknik özellikleri [24].

\begin{tabular}{|c|c|c|}
\hline Özellik & Sembol & Değer \\
\hline Tip & & $6 \mathrm{~L} 20$ \\
\hline Silindir Çap1 & $\mathrm{D}$ & $200 \mathrm{~mm}$ \\
\hline Silindir Kesit Alanı & $\mathrm{A}_{\mathrm{c}}$ & $31400 \mathrm{~mm}^{2}$ \\
\hline Strok & $2 \mathrm{r}$ & $280 \mathrm{~mm}$ \\
\hline Biyel Boyu & $\mathrm{L}$ & $630 \mathrm{~mm}$ \\
\hline Güç & & $1200 \mathrm{~kW}$ \\
\hline Efektif Basınç & $\mathrm{P}$ & $28 \mathrm{bar}$ \\
\hline Silindir Sayısı & $\mathrm{N}$ & 6 \\
\hline Bağlantı Oranı & $\mathrm{r} / \mathrm{L}$ & 0,22 \\
\hline Dönen Kütleler & $\mathrm{m}_{\mathrm{d}}$ & $32,5 \mathrm{~kg}$ \\
\hline Ötelenen Kütleler & $\mathrm{m}_{\ddot{o}}$ & $54,8 \mathrm{~kg}$ \\
\hline Krank Mili Açısal H1zı & $\omega$ & $94 \mathrm{rad} / \mathrm{s}$ \\
\hline Krank Açı1 & $\theta$ & \\
\hline
\end{tabular}

\section{Tasarım kriterleri}

Jeneratör kaidesinin geometrisine, yapısına ve biçimine karar verirken dikkat edilmesi gereken belirli etkiler ve standartlar vardır $[25,26]$. Bu parametreler aşağıdaki gibidir.

- Gemi teknesinin endazesi ve gideceği rotanın meteorolojik özellikleri.

- Gemi jeneratörünün 3 düzlemdeki ölçüleri, destek elemanları, kaide içerisinden geçecek olan boru devreleri, güç iletim mekanizmasının konumu ve atık hava tahliye sistemi gibi konstrüksiyonun bütününe ait elemanlar.

- Dizel jeneratörünün görev tanımı, hangi düzlemde hareketli elemanların bulunduğu, setin hareketli veya sabit olması.

- Jeneratör sisteminin içinde yer alan elemanların statik ve dinamik yük paylaşımı, bakım esnasında paylaşılacak yüklerin belirlenmesi, işletim esnasında oluşacak maksimum kuvvetlerin belirlenmesi.

- Kurulum ve bakım esnasında kolay erişebilirlik, geometrik yerleştirme sınırları çevresindeki tanklar ile arasındaki mesafe, makina dairesinin belirli şartlardaki sıcaklıkları gibi işletim zorunlulukları.

- Bakım ve arıza durumunda her noktaya ulaşmak için konumlandırılması gereken ara panel güverteler ve değiştirilmesi gereken parça olduğunda transport için vinç erişebilirliği.

- Kurulum ve işletim maliyetlerinin belirlenmesi, tasarımın ömrü, parça yenilenmesi maliyeti gibi ekonomik sınırlamalar.

- Yeniden değerlendirilebilirliği ya da tekrar kullanılabilirliği gibi çevre etmenleri. 
- Jeneratörün yeteri kadar konstrüktif desteğinin bulunup bulunmadığı, kaide konumlandırılırken altındaki enine elemanların (posta) ve boyuna elemanların (tülanilerin) sayısı ve sac kalınlıkları gibi mekanik sınırlandırmalar.

Bu çalışmada yapılan ve farklı açılardaki boru profillerden oluşan tasarımın teknik resmi Şekil 3'te verilmiştir. Boru profillerin diş çap $120 \mathrm{~mm}$, et kalınlığı ise $10 \mathrm{~mm}$ 'dir. Bu değerler statik emniyet değerlerinin sağlanabilmesi için seçilmiş değerlerdir.

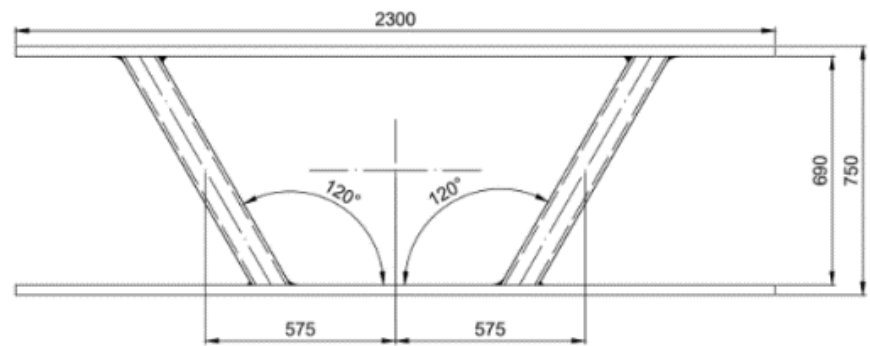

Şekil 3. Jeneratör kaide tasarımı.

Çalışmada, Şekil 3'te görülen ve $120^{\circ}$ ile gösterilen açı, $40^{\circ}$ ile $140^{\circ}$ arasında değiştirilerek 11 farklı tasarım oluşturulmuştur (Şekil 4). Tüm bu tasarımlar için ayrı ayrı ikaz kuvvet ve momentleri hesaplanarak sonlu eleman analizi yapılmış ve sonuçlar irdelenmiştir.

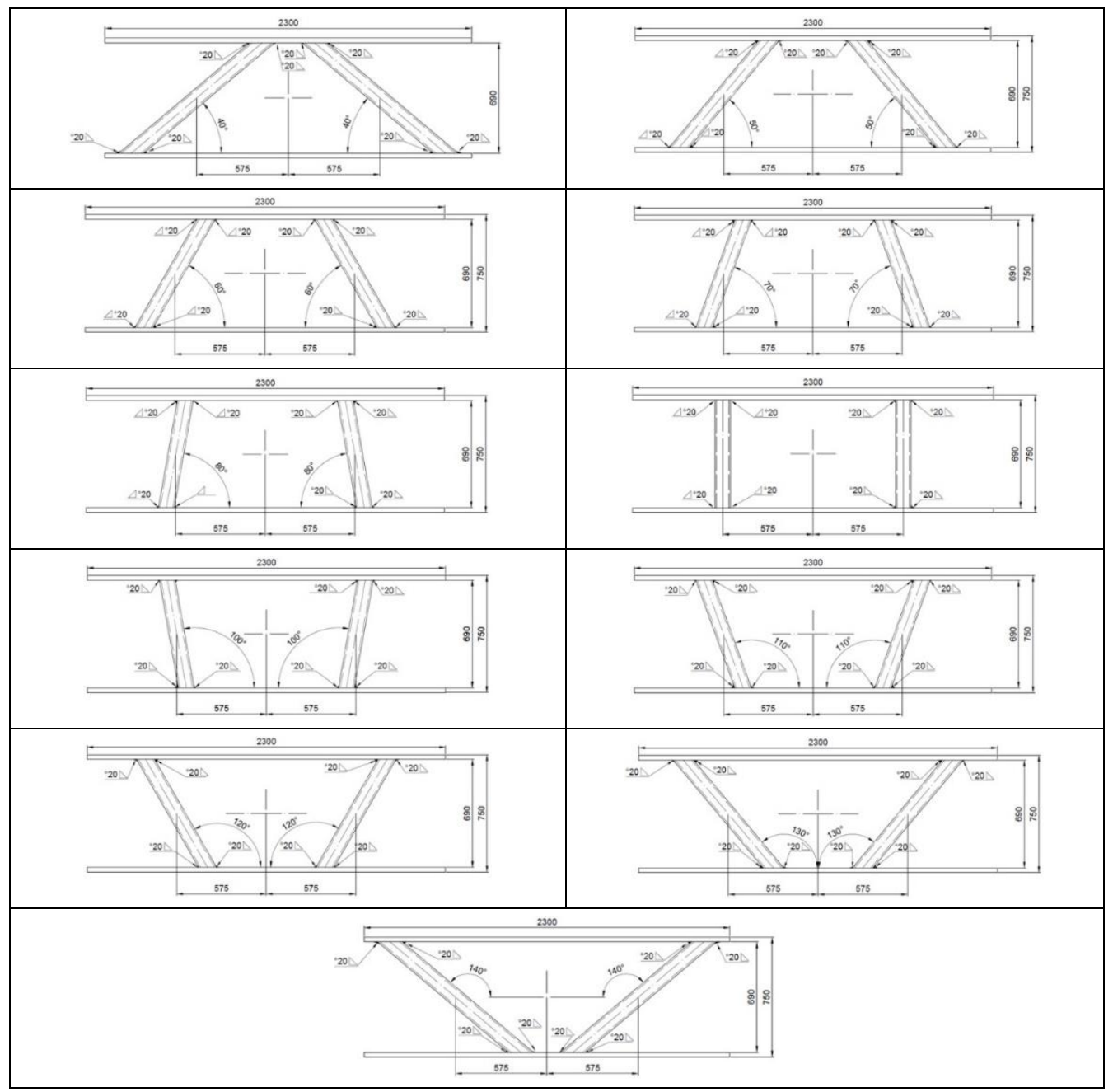

Șekil 4. Tüm tasarımlar. 
Aşağıda, tasarımı yapılan kaidenin diğer kaide türlerine göre çeşitli üstünlüklerinden bahsedilmektedir. Bu üstünlüklerden bazıları şunlardır.

- Kaideler statik ve dinamik yüklemelere karşı oldukça dayanıklıdır.

- Tasarlanan kaide çeşidinin fazla olması, en optimum çözüm için geniş bir yelpaze oluşturmaktadir.

- Kaide tasarımında açısal değişimlerden yararlanılmış, dikey ve yatay uzunluklar korunmuştur. Böylelikle kaideler arasındaki maliyet farkı çok azdır.

- Kaide imalatında sadece kaynak kullanılmıştır. Diğer kaide tiplerine bakıldığında, bu tasarımda modellenen kaideler daha kolay imal edilebilir şekildedir.

- Kaidelerin gemiye montajında bir zorluk bulunmamaktadır. Jeneratör seti gemiye yerleştirilmeden önce kaideler yerleştirilir, sonrasında jeneratör seti bu kaidelerin üzerine oturtulur.

- Kaidelerin yapısında çok çeşitli elemanlar ve detaylar bulunmadığı için tasarlanması diğer kaide tiplerine göre daha kolaydır.

- Kaideyi oluşturan ayaklar birbirinden bağımsız olduğu için imalat hatası gibi durumlarda hatalı parçanın yeniden imali daha hızlı, kolay ve aynı zamanda ekonomiktir.

\section{Kuvvet ve moment hesapları}

Türbin, pres, kompresör, jeneratör gibi makinaların yataklarının statik ve dinamik yüklerinin etki ettiği kaideler ve bağlı oldukları yüzeyler, maruz kaldıkları kuvvetlere karşı direnç gösterebilmelidirler. Makinaların oturduğu yüzeyler tasarlanırken çalışma yeri, çalışma süresi, operasyon bölgesindeki sarsıntılar dikkate alınmalı ve zemin tasarımında karşılaşabilecek her türlü yük dikkate alınmalıdır. Operasyon yük karakteristiği makinanın geometrisine, hızına, konumuna ve sınıflandırılmasına bağlıdır. Gemi jeneratörü dinamik olarak ele alındığında dikkate alınması gereken temel etkenler operasyon sırasında oluşacak olan kuvvetler ve bu kuvvetlerin jeneratörün kendisine ve bağlantısı bulunduğu diğer elemanlar üzerindeki etkileşimidir. Pistonun doğrusal hareket etmesi ve krank milinin dairesel hareket etmesi atalet kuvvetlerinin hesaplanmasinı basitleştirir. Fakat aynı durum biyel kolunun hareketi ne doğrusal ne de dairesel olarak tanımlanamadığından geçerli değildir. Biyel kolu elipse benzer bir hareket oluşturduğundan atalet kuvvetinin hesaplamaları daha zordur. $\mathrm{Bu}$ zorlu hesap bazı kabuller eşliğinde basite indirgenebileceği gibi sonlu elemanlar yöntemi ile de hesaplanabilir. [27]

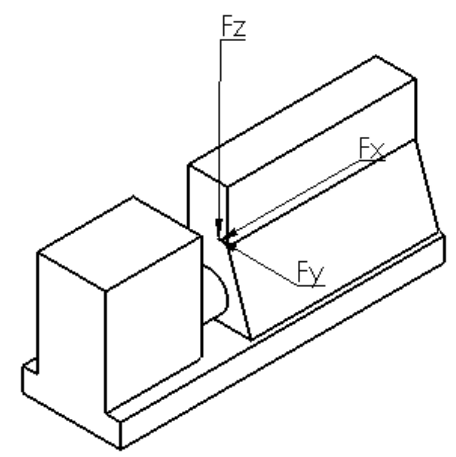

Şekil 5. Jeneratör setine etkiyen dengesizlik kuvvetleri [28]. 
İçten yanmalı bir motorun bir silindirindeki düşey ve yatay dengesizlik kuvvetleri olan $\mathrm{F}_{\mathrm{y}}$ ve $F_{z}$ şu şekilde tanımlanır. Genelde yatay $F_{x}=0$ olarak kabul edilir. (Şekil 5)

$F_{y}=m_{d} r \omega^{2} \sin \theta$

$F_{z}=m_{d} r \omega^{2} \cos \theta+m_{\ddot{0}} r \omega^{2}\left(\cos \theta+\Lambda_{e} \cos 2 \theta\right)$

Burada; $m_{d}$ krank kolunun ve bağlantı çubuğunun dönen dengesizlik kütlesi, $m_{0}$ ise piston ve bağlantı çubuğunun eksenel hareketli kütlesidir. $\omega$ da krank milinin açısal hızıdır. Birinci ve ikinci mertebeden bileşenleri ayıran kuvvetler şu denklemlerle gösterilebilir.

$F_{z 1}=\left(m_{d}+m_{\ddot{\mathrm{o}}}\right) r \omega^{2} \cos \theta$

$F_{z 2}=m_{\ddot{0}} r \omega^{2} \Lambda_{e} \cos (2 \theta)$

Birinci ve ikinci mertebeden kuvvetleri ayrıntılı incelenirse bir motorun çalışma fazları sonucunda ortaya çıkan harmonik ikazın 2 çeşit bileşeni olduğu söylenebilir. Bu ikaz bileşenlerine ayrılırsa, bunlar 1 . harmonik ve 2 . harmonik bileşen olarak adlandırılabilir. Tablo 1'deki değerlerin formüllerde yerine konulması ile bulunan kuvvet değerlerinin krank açısına bağlı olarak değişimleri Şekil 6'da gösterilmiştir. Dizel motor 6 silindirli ve 4 zamanlı olup, bir güç çevrimi krank milinin 2 tur tam dönüşüyle yani 720 krank mili açısıyla tamamlanmaktadır.

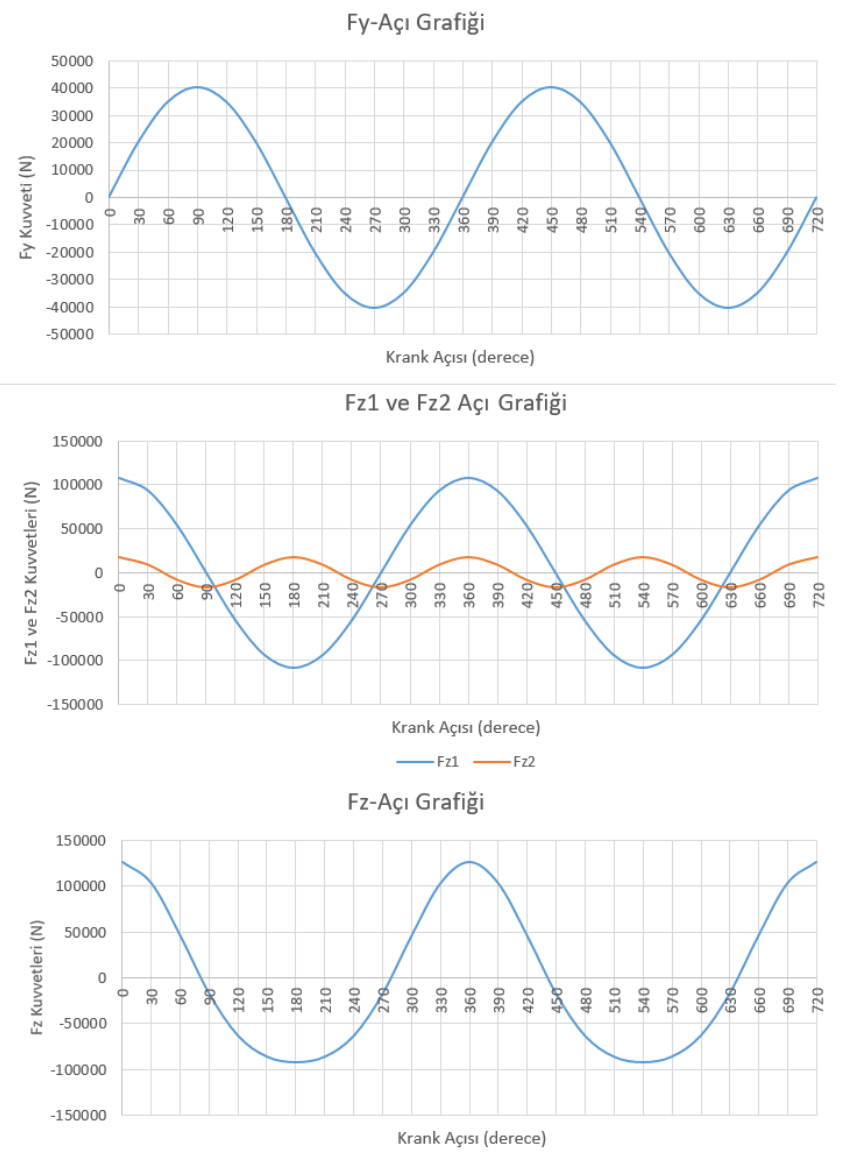

Şekil 6. Kuvvetlerin krank mili açısına göre değişimi. 
Buna göre 6 silindirli motorun düşey ve yatay dengesizlik kuvvetleri;

$$
\begin{aligned}
& F_{y}=m_{d} \cdot r \cdot \omega^{2} \cdot \sin \left(\sum_{i=1}^{n}\left(\theta+\alpha_{e, i}\right)\right) \\
& F_{z}=m_{d} \cdot r \cdot \omega^{2} \cdot \cos \left(\sum_{i=1}^{n}\left(\theta+\alpha_{e, i}\right)\right)+m_{\ddot{0}} \cdot r \cdot \omega^{2} \cdot\left(\cos \left(\sum_{i=1}^{n}\left(\theta+\alpha_{e, i}\right)\right)+\right. \\
& \left.\left(\frac{r}{L}\right) \cdot \cos \left(\sum_{i=1}^{n} 2\left(\theta+\alpha_{e, i}\right)\right)\right) \\
& \alpha_{e, i}=\frac{720^{0}}{n}=120^{\circ}
\end{aligned}
$$

olarak belirlenir. Daha önceden belirtildiği gibi, jeneratör setindeki titreşimin ve dengesizliğin en büyük nedeni 1 . ve 2 . dereceden meydana gelen kuvvetler ve momentlerdir. Bunların önem derecesini belirleyen önemli etmenler bu kuvvetlerin ve momentlerin büyüklüğü, jeneratör seti üzerinde etkidikleri yerler ve jeneratördeki diğer fiziksel büyüklüklerle olan ilişkilerdir (örneğin doğal frekans). Şekil 7'de de açıkça görüldüğü üzere, jeneratör setine etkiyen 3 ana moment vardır.

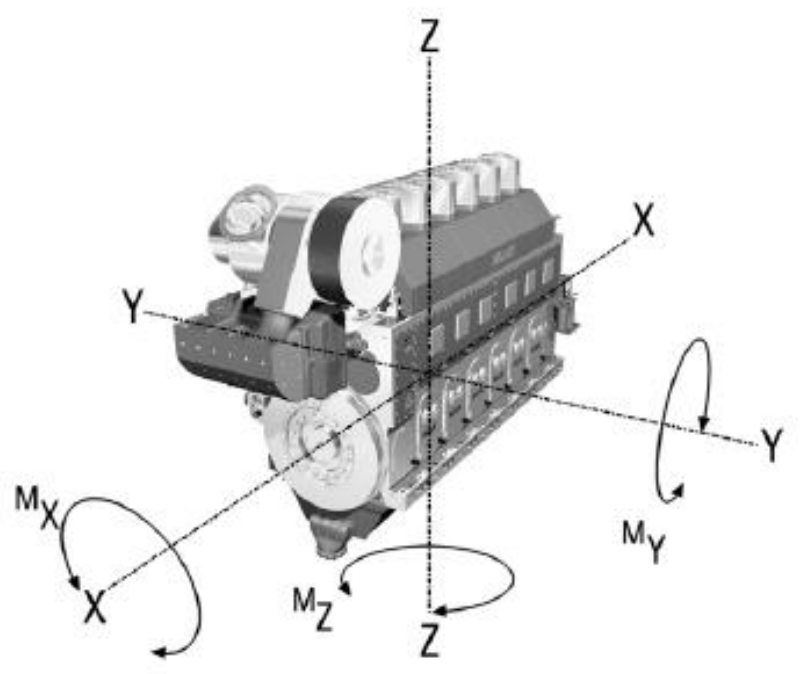

Şekil 7. Jeneratör motoruna etki eden momentler.

Yine tek silindir için bilinen moment ifadelerinden faydalanılarak 6 silindirli motorun ikaz momentleri aşağıdaki şekilde elde edilir.

$$
\begin{aligned}
& M_{x}=6 \cdot\left(H_{T N G, k}\right) \cdot A_{c} \cdot r \cdot \sin (6 \theta) \\
& M_{y}=m_{d} \cdot r \cdot \omega^{2} \cdot\left(\sum_{i=1}^{n}\left(\ell_{i} \cos \left(\theta+\alpha_{e, i}\right)\right)\right)+m_{\ddot{0}} \cdot r \cdot \omega^{2} \cdot\left(\left(\sum_{i=1}^{n}\left(\ell_{i} \cos \left(\theta+\alpha_{e, i}\right)\right)\right)+\right. \\
& \left.\left(\frac{r}{L}\right) \cdot\left(\sum_{i=1}^{n}\left(\ell_{i} \cos 2\left(\theta+\alpha_{e, i}\right)\right)\right)\right) \\
& M_{z}=m_{d} \cdot r \cdot \omega^{2} \cdot\left(\sum_{i=1}^{n}\left(\ell_{i} \sin \left(\theta+\alpha_{e, i}\right)\right)\right)
\end{aligned}
$$


Faz farkları, silindir sayısı ve ateşleme sırası göz önüne alınarak 6 silindirli motorun moment değerleri hesaplanarak aşağıdaki sonuçlar elde edilmiş olup Şekil 8'de gösterilmiştir.

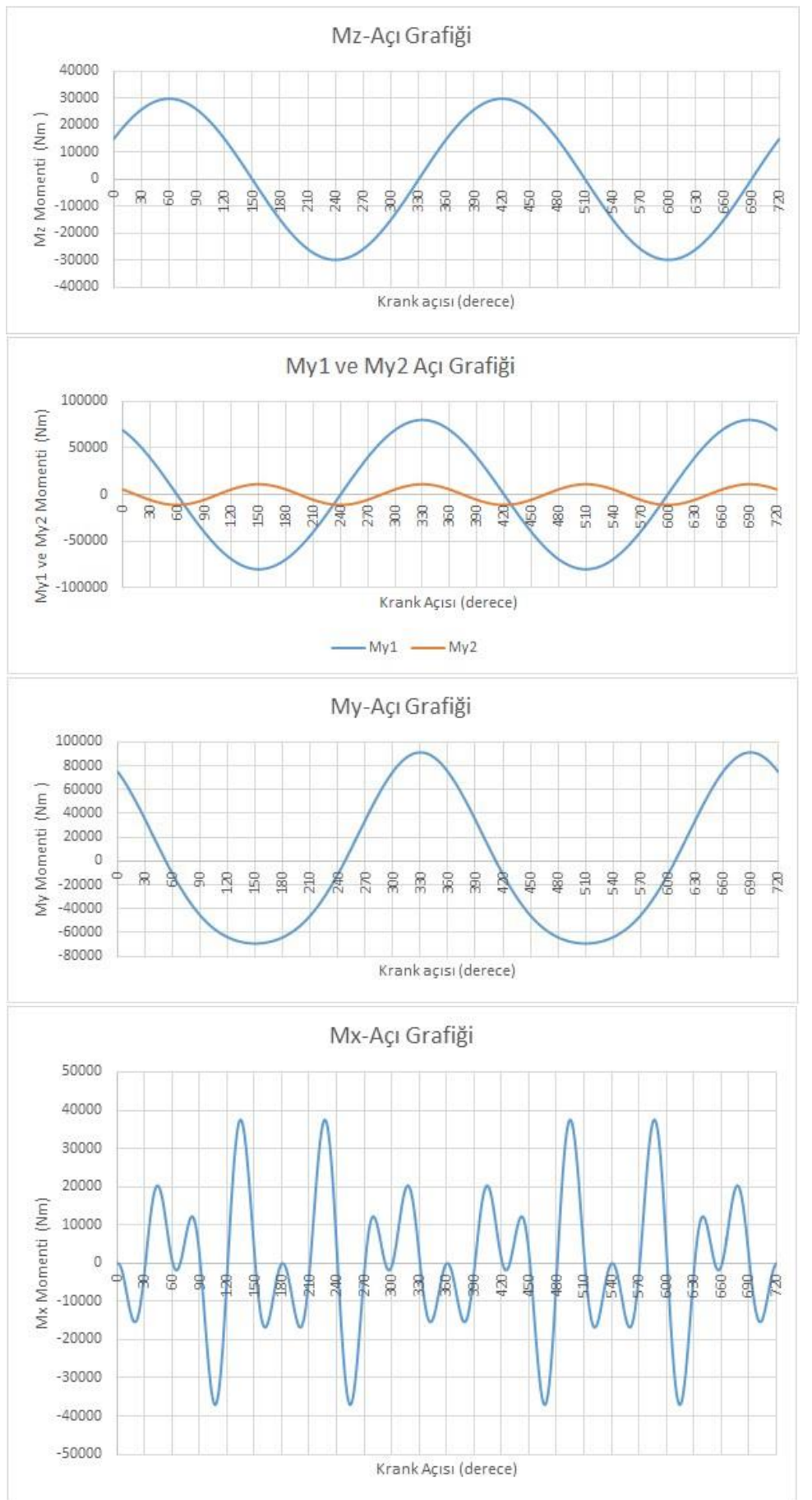

Şekil 8. Momentlerin krank mili açısına göre değişimi.

Yapılan analitik hesaplar sonucu motor üzerinde $\mathrm{M}_{\mathrm{y} 1}$ momentinin $\mathrm{M}_{\mathrm{y} 2}$ momentinden daha etkin olduğu açıkça görülmektedir. Silindir sayısına ve ateşleme sırasına göre momentler değişiklik gösterebilmektedir ve hatta kuvvetlerde olduğu gibi dengelenmeleri veya sıfıra eşit olmaları söz konusu olabilir. 


\section{Analizler}

Çalışmanın bu bölümünde modellenen jeneratör ve kaide tasarımları üzerinde önce modal analiz, sonrasında ise harmonik (steady-state) analiz yapılmıştır. Analizler ANSYS ile yapılırken, jeneratör seti için belirlenen modelin çizimi (Şekil 9) SOLIDWORKS programında gerçekleştirilmiştir. Yapılan literatür araştırması sonucu jeneratör modellemesi gerekli boyutlar çerçevesinde aşağıda görüldüğü gibi modellenmiştir.

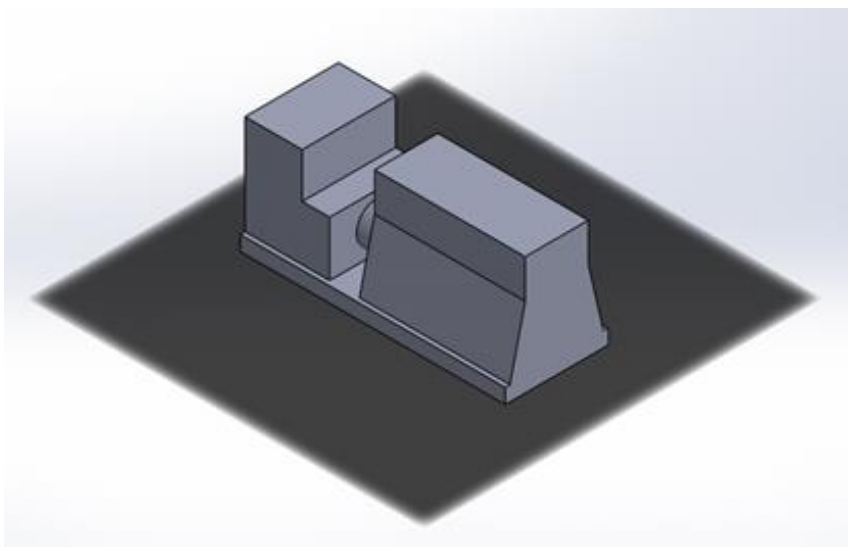

Şekil 9. Modellenen jeneratör seti.

Seçilen kaideler, modellenen jeneratör ile beraber Şekil 10'da sonlu eleman modeli gösterilen geminin makina dairesi tabanına yerleştirilmiştir (Şekil 11).

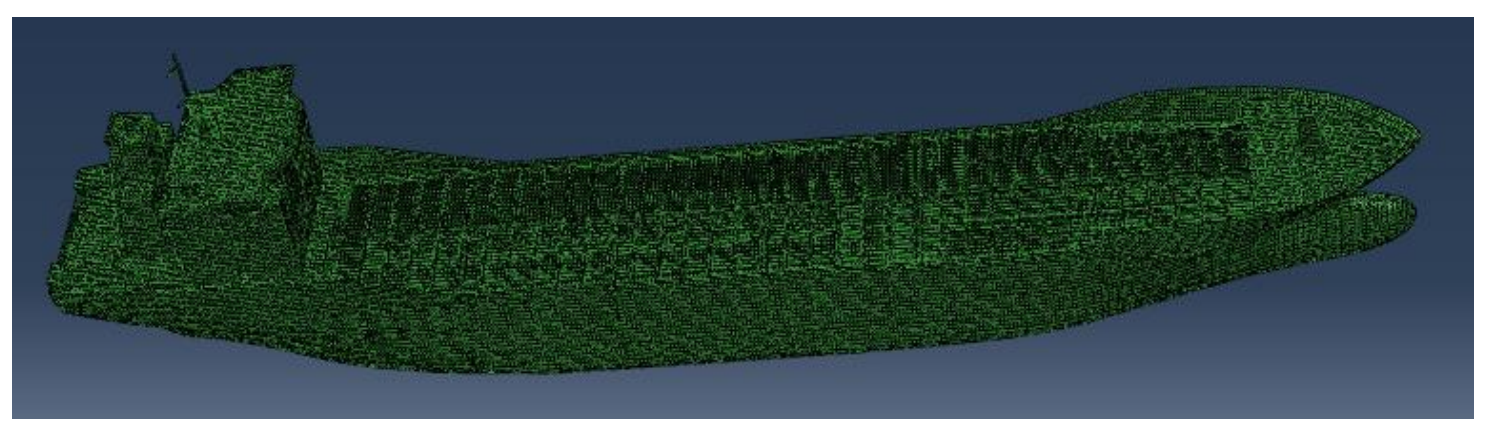

Şekil 10. Analiz için kullanılan geminin sonlu eleman modeli.

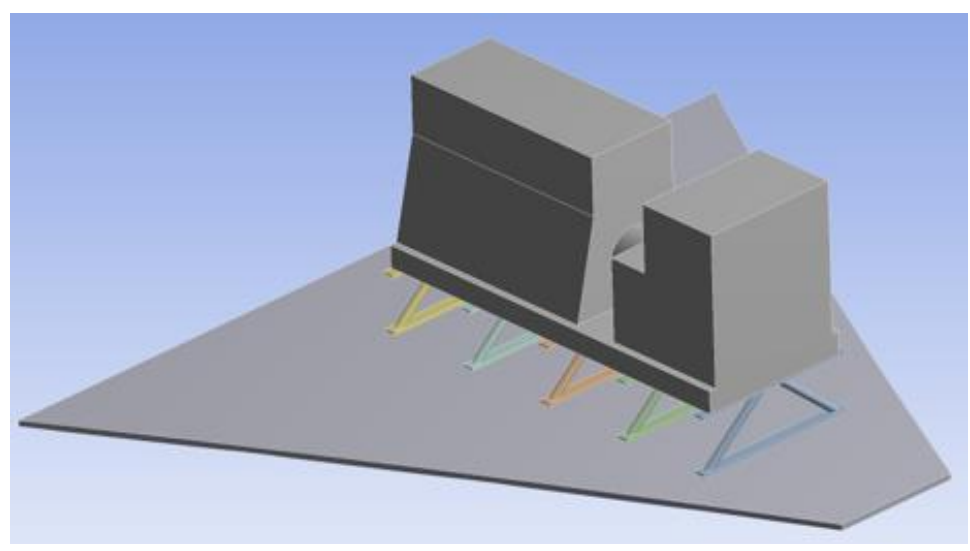

Şekil 11. Makina dairesi zeminine kaidelerin ve jeneratörün yerleştirilmesi. 
11 farklı kaide tasarımına ek olarak kaidesiz jeneratör modeli de aynı şekilde sonlu elemanlar programında analiz edilmiştir. Jeneratör seti rijit bir yapı olarak modellenirken, kaideler ve gemi ise esnek olarak modellenmiştir. Eleman boyutu ortalama $40 \mathrm{~mm}$ olup et kalınlıkları tek elemanla geçilmiştir. Eleman türü olarak lineer tetrahedral elemanlar kullanılmıştır. Jeneratör kaidelere, kaideler ise zemine ankastre olarak bağlanmıştır. Tablo 2'de analizlerle ilgili detaylar verilmiştir.

Tablo 2. Sonlu eleman analiz değerleri.

\begin{tabular}{|c|c|c|}
\hline Kaide Aç1S1 (derece) & Eleman Say1s1 & Düğüm Say1s1 \\
\hline 40 & 36590 & 75642 \\
\hline 50 & 35542 & 72918 \\
\hline 60 & 32366 & 67278 \\
\hline 70 & 30463 & 63762 \\
\hline 80 & 30439 & 63539 \\
\hline 90 & 30114 & 63052 \\
\hline 100 & 30634 & 63802 \\
\hline 110 & 30449 & 63766 \\
\hline 120 & 32636 & 67645 \\
\hline 130 & 35632 & 73073 \\
\hline 140 & 36944 & 76148 \\
\hline
\end{tabular}

Ardından tasarlanan 11 farklı tipte kaide sırasıyla ANSYS programında analiz edilmiştir. Şekil 12 ve Şekil 13 'te örnek olarak sırasıyla kaidesiz ve $40^{\circ}$ açılı kaide modelinin analizleri gösterilmiştir [29, 30].

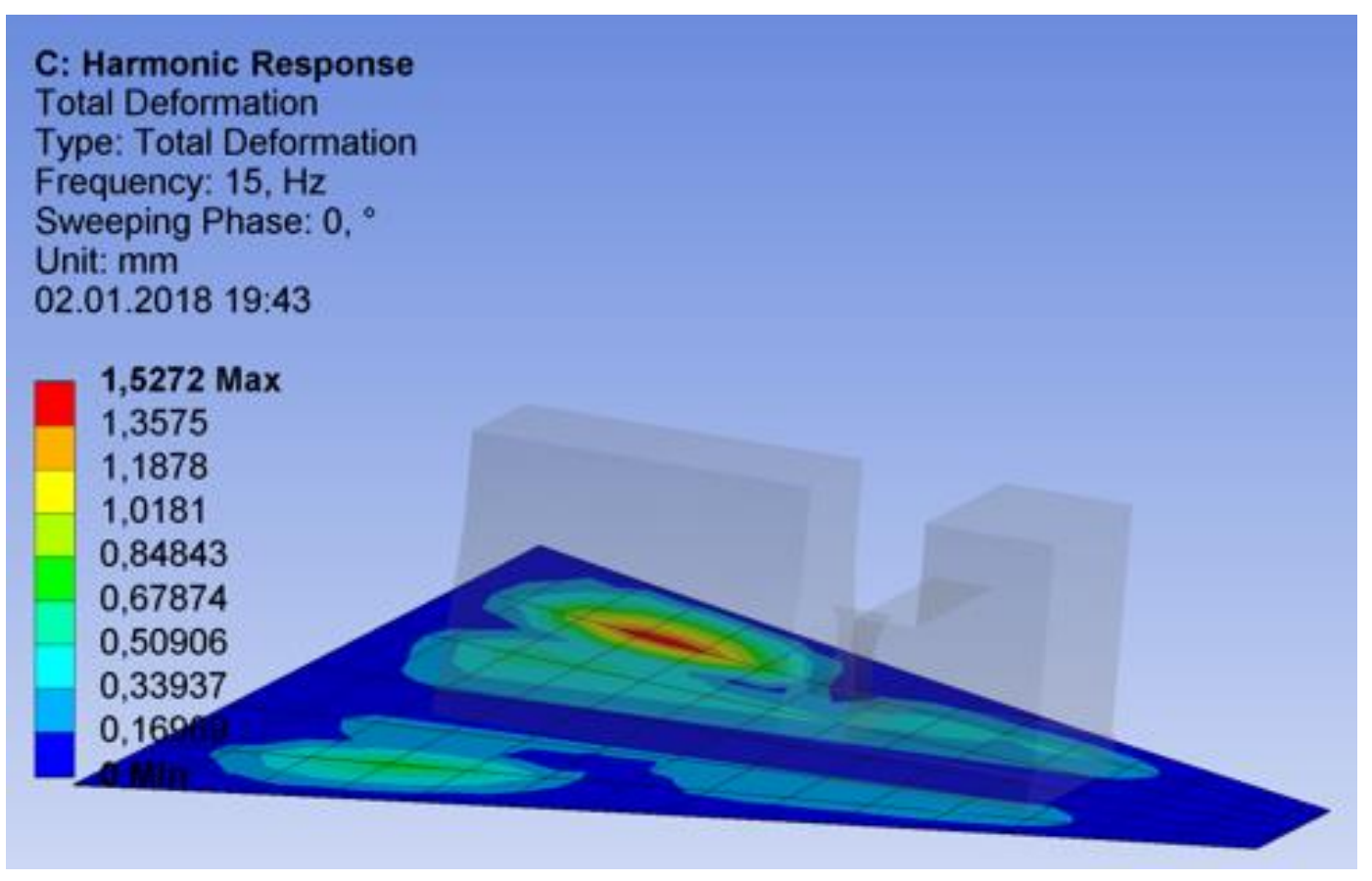

Şekil 12. Jeneratör setinin kaidesiz modellenmesi sonucu oluşan toplam deformasyon. 


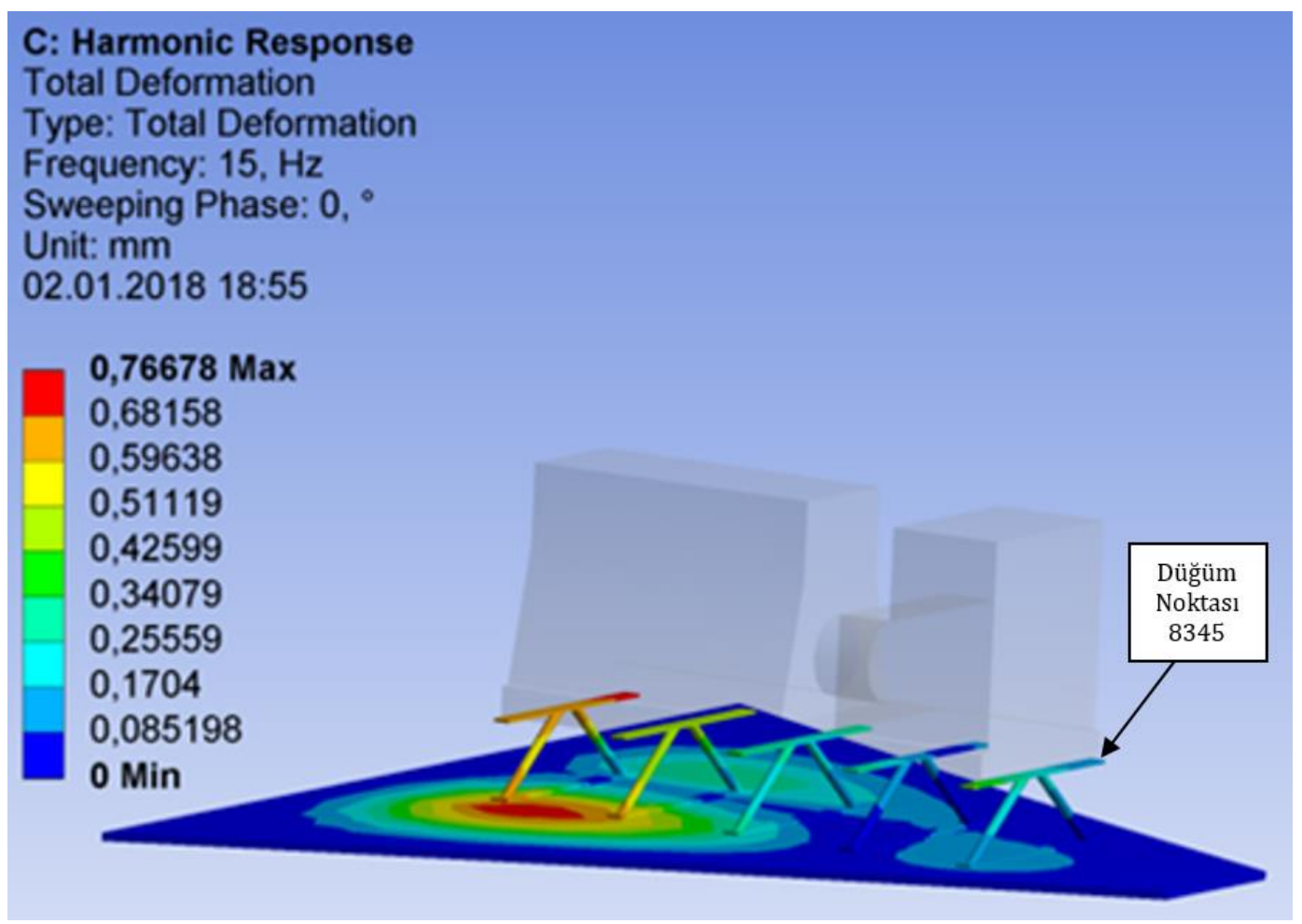

Şekil 13. 40 Derecelik kaide tasarımı ile oluşan toplam deformasyon.

Şekil 12 ve Şekil 13'te de gösterildiği gibi 12 farklı analiz sonucu alınmıştır. Bu alınan sonuçlarda kıyaslama ve optimum sonuca ulaşmak adına gemi makina dairesi, jeneratör seti ve kaideler üzerinde toplamda 10 farklı dügüm noktası belirlenmiş, tüm bu düğüm noktalarına ait yer değiştirme değerleri gemi jeneratörünün çalışma frekansında incelenmiştir. Şekil 14'te örnek olarak model üzerindeki bir dügüum noktası için yer değiştirme grafiği gösterilmiştir. Bu grafiklerin tümü incelendiğinde her düğüm noktası için benzer sonuçlar elde edildiği görülmüştür.

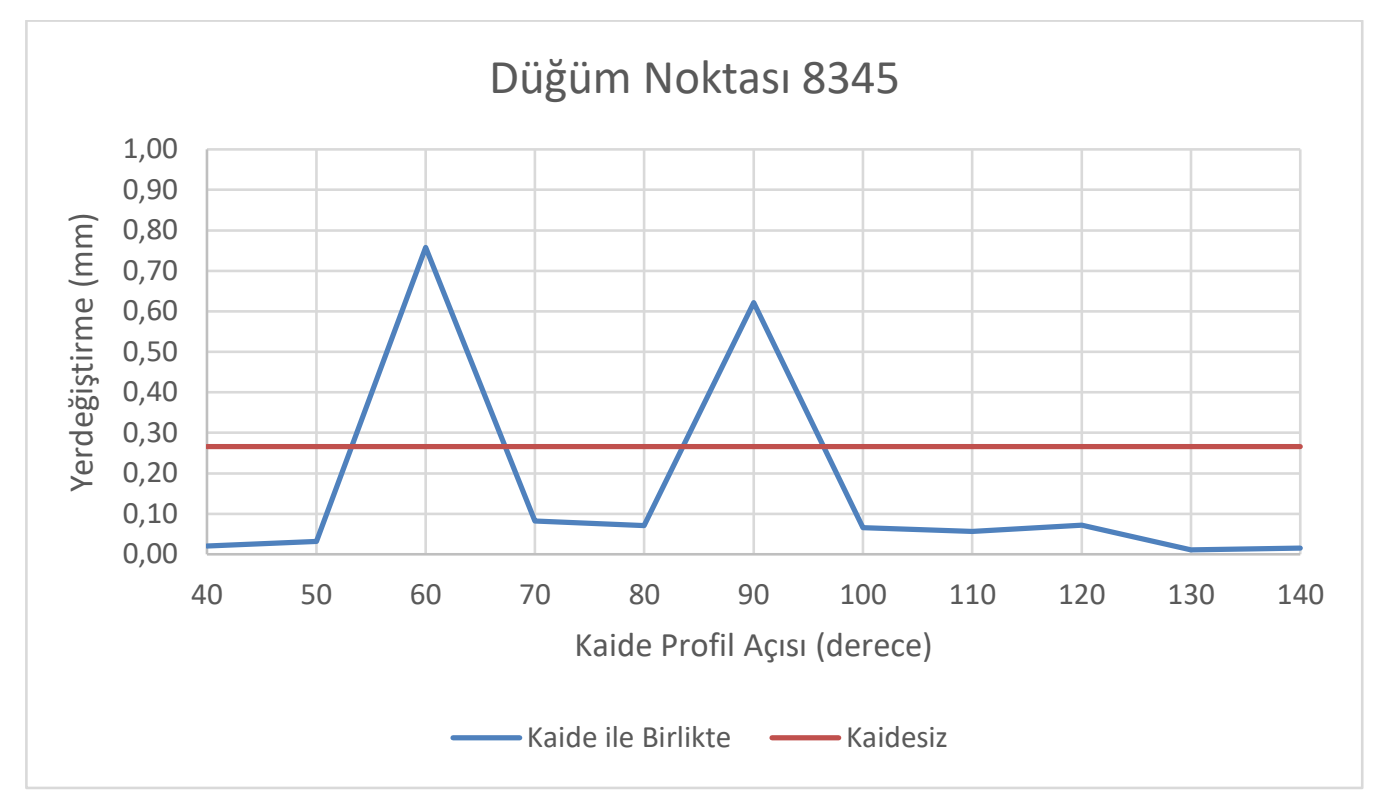

Şekil 14. 8345 No.'lu düğüm noktası için total deformasyon grafiği. 


\section{Sonuç ve değerlendirme}

Dizel jeneratör setleri için yapılan çeşitli kaide tasarımlarının harmonik titreşim analizleri sonucunda, gemi, jeneratör ve kaideler üzerinde seçilen birçok noktanın deformasyon durumları, kaidesiz duruma göre grafikler halinde gösterilmiştir. Yapılan analizler sonucunda ortaya çıkan grafikler değerlendirildiğinde tasarlanan kaidelerin, titreşim sonucu oluşan, istenmeyen deformasyonlar üzerinde olumlu sonuçları gözlenmiştir. Toplam deformasyona bakıldığında, birkaç düğüm noktasında ve doğrultuda olumsuz sonuçlar alındığı görülse de çok büyük oranda 60 ve 90 derecelik kaide tasarımları dışındaki kaidelerin titreşim azaltıcı etkileri açıkça görülmektedir. Tüm dügüm noktaları ve kaide tasarımlarından elde edilen grafikler incelendiğinde 120 ve 130 derecelik kaide tasarımlarının en iyi sonucu verdiği gözlemlenmiştir. Bazı düğüm noktalarında standartların üstünde kalan deformasyon değerlerinin kaide uygulamasından sonra ciddi oranda limitlerin altında kaldığı açıkça görülmektedir. Ayrıca 60 ve 90 derecelik kaide tasarımlarında deformasyon değerleri çok yüksek düzeylere çıkmakta olup bu açılardaki tasarımların bu sistem için kesinlikle uygun olmadığı açıkça görülmektedir. Sonuç olarak, yapılan tasarım ve analizler neticesinde, dizel jeneratör setleri ile gemi makina dairesi zemini arasında, titreşim sonucu oluşan deformasyon değerlerinin azaltılması amaciyla tasarlanmış olan kaidelerin büyük oranda olumlu sonuçlar verdiği gözlemlenmiş olup çalışmanın genişletilmesi açısından tasarlanan bu yapıların, deneysel olarak da doğrulanması yararlı olacaktır.

\section{Kaynaklar}

[1] Guidance Notes on Ship Vibration, American Bureau of Shipping, (2006).

[2] International Standard ISO 6954, Mechanical vibration and shock, Guidelines for the Overall Evaluation of Vibration in Merchant Ships, (1984).

[3] Chavan, V. S., Askhedkar, R. ve Sanap, S. B., Analysis of anti vibration mounts for vibration isolation in diesel engine generator set, International Journal of Engineering Research and Applications, 3, 3, 423-1428, (2013).

[4] Fucai, H., Jianguo, Y. ve Qingming, Z., Analysis and experimental research on two layers vibration isolation of diesel generating set in superiority oil tanker, Proceedings, The Eighth International Conference on Electronic Measurement and Instruments, China, (2007).

[5] Prakash, S. ve Puri, V. Y., Foundations for dynamic machines, Journal of Structural Engineering, Special Issue, Madras, India, (2006).

[6] Gerb Vibration Control Systems, Mass Dampers, http://www.gerb.com/, (20.04.2016)

[7] Clunis, G. E. ve Bradley S. J., Development of diesel generator isolation systems for low noise and vibration, Journal of the Canadian Acoustical Association, 19, 4, (1991).

[8] You, D., Sun, L., Ai, S. ve Liu, Y., Research on the vibration characteristics of a ship engine-base system, Advanced Materials Research, 644, 239-242, (2013).

[9] Daifuku, M., Nizhizu, T., Takezawa, A., Kitamura, M., Terashita, H. ve Ohtsuki, Y., Design methodology using topology optimization for anti-vibration reinforcement of generators in a ship's engine room, Journal of Engineering for the Maritime Environment, doi: 10.1177/1475090214543081, (2014). 
[10] Mogal, S. P., Behera, R. K. ve Pawar, S. Y., Design and development of muffler for diesel generator set for reduction of noise, International Journal of Engineering Science and Technology (IJEST), 3, 4, 3591-3595, (2011).

[11] Bognatz, S. R., Alignment of critical and non critical machines., Orbit, 4, 23-25, (1995).

[12] Sadok, S., Characterization and experimental validation of the dynamic behavior of an industrial turbo-alternator supporting structure, International Journal on Numerical and Analytical Methods in Engineering (IRENA), 2, 2, (2014).

[13] Listewnik, K., Influence of Vibration of Ship's Generating Set on Emitted Acoustic Energy, (2019).

[14] Gawande, S. H., Navale, L. G., Nandgaonkar, M. R. ve Butala, D., Torsional frequency analysis of multi-cylinder inline diesel engine generator system, Proceedings, The International Conference on Mechanical, Industrial, and Manufacturing Technologies (MIMT '10), 519-524, ASME, January, (2010).

[15] Anton, G. P., Paval, M. ve Sorel, F., Application on an updated finite element model of an engine in the automotive industry, Proceedings, SISOM 2011, 6874, Bucharest, May, (2011).

[16] Livshits, A., Dynamic analysis and structural design of turbine generator foundations, Proceedings, European Built Environment CAE Conference, (2008).

[17] Adhikari, S., Handbook of turbo-generator foundation, Lap Lambert, (2018).

[18] Murali, K. ve Madan, R., M-CAD centre, MSRSAS, 20-23, http://www.msrsas.org/docs/sastech_journals/archives/Sept2003/5.pdf, (2003).

[19] Lee, D. C., Brennan, M. J. ve Mace, B. R., Dynamic behaviour and transmission characteristics of structure-borne noise of marine diesel engine generator with resilient rubber mounts and elastic foundation, Academic Report, University of Southampton Institute of Sound and Vibration Research, England, (2004).

[20] Aher, P. B. ve Malave, S. K., Vibration assessment of diesel engine genset mounts, Proceedings, International Conference on Ideas, Impact and Innovation in Mechanical Engineering, 5, 6, 1700-1706, (2017).

[21] Adeoye, O. S., Adebayo, A. A., Olofinjana, A. ve Tafa, A. K., An overview of methods of reduction of vibration for diesel generators, Journal of Electrical and Electronical Systems, 8, 1, 296, (2019).

[22] Dimbale, N., Bhujbal, A., Hanabar, R. ve Gawande, S., Noise and vibration analysis of 6 cylinder diesel engine of SL 90 type, Proceedings, IJSAT, 1, 2, (2011).

[23] Yücel, A., Gemilerde ortaya çıkan yerel titreșim problemlerinin teorik ve deneysel analizi, Doktora Tezi, İstanbul Teknik Üniversitesi, Fen Bilimleri Enstitüsü, İstanbul, (2009).

[24] Wärtsilä Ship Power Engines, WÄRTSILÄ 26 Project Guide, http://www.wartsila.com/docs/default-source/product-files/engines/msengine/wartsila-o-e-w-26-pg.pdf, (23.01.2016).

[25] University of Rijeka Faculty of Maritime Studies, Auxiliary Marine Machinery, http://www.pfri.uniri.hr/ bopri/documents/23_AuxiliaryMarineMachinery_000. pdf, (21.06.2016).

[26] Lee, J. P. ve Golod, Y. S., Foundations for dynamic equipment, American Concrete Institude, (2011).

[27] Sağlam, H., Gemi dizel motorunun çalışması esnasında ayak basma yerlerinde oluşan kuvvetlerin analizi, Yüksek Lisans Tezi, İstanbul Teknik Üniversitesi, Fen Bilimleri Enstitüsü, İstanbul, (2013). 
[28] MAN Diesel \& Turbo, Marine GenSets, https://marine.man.eu/docs/librariesprovider6/marine-broschures/1510-003606ppr_marinegensets_low.pdf?sfvrsn=2, (05.02.2016).

[29] Kutay, M. G., Mukavemet değerleri kitabı, TMMOB Makina Mühendisleri Odası Yayınları, (2004).

[30] ESTEQ, Modal analysis: What it is and is not., https://esteq.co.za/2014/11/25/modal/comment-page-1/\#comments. (17.07.2017). 